\title{
Value of probe-based confocal laser endomicroscopy ( $p C L E)$ and dual focus narrow-band imaging (dNBI) in diagnosing early squamous cell neoplasms in esophageal Lugol's voiding lesions
}

Authors

Institutions
Piyapan Prueksapanich ${ }^{1}$, Rapat Pittayanon ${ }^{1}$, Rungsun Rerknimitr ${ }^{1}$, Naruemon Wisedopas² ${ }^{2}$ Pinit Kullavanijaya

Division of Gastroenterology, Department of Medicine, Faculty of Medicine, Chulalongkorn University, Bangkok 10330, Thailand

${ }^{2}$ Department of Pathology, Faculty of Medicine, Chulalongkorn University, Bangkok 10330, Thailand submitted

10. November 2014 accepted after revision 20. February 2015

\section{Bibliography}

Dol http://dx.doi.org/

10.1055/s-0034-1391903

Published online: 13.4.2015

Endosc Int Open 2015; 03:

E281-E288

(c) Georg Thieme Verlag KG

Stuttgart · New York

E-ISSN 2196-9736

\section{Corresponding author}

\section{Rungsun Rerknimitr, MD}

Division of Gastroenterology Department of Medicine

Faculty of Medicine

Chulalongkorn University

Bangkok 10330

Thailand

Fax: +66-2-2527839

ERCP@live.com
Background and study aims: Lugol's chromoendoscopy provides excellent sensitivity for the detection of early esophageal squamous cell neoplasms (ESCN), but its specificity is suboptimal. An endoscopy technique for real-time histology is required to decrease the number of unnecessary biopsies. This study aimed to compare the ESCN diagnostic capability of probed-based confocal laser endomicroscopy (pCLE) and dual focus narrow-band imaging (dNBI) in Lugol's voiding lesions.

Patients and methods: Patients with a history of head and neck cancer without dysphagia were recruited. Lugol's voiding lesions larger than $5 \mathrm{~mm}$ were sequentially characterized by dNBI and pCLE by two independent operators. Finally, all lesions larger than $5 \mathrm{~mm}$ were biopsied followed by histological analysis, which is considered to be the gold standard in cancer diagnosis. The primary outcomes were the sensitivity, specificity, positive predictive value (PPV), negative predictive value (NPV), and the accuracy of the two techniques.

Results: In total, 44 patients were enrolled with a mean age of 60 years; $80 \%$ were male. Twentyone Lugol's voiding lesions larger than $5 \mathrm{~mm}$

\section{Introduction}

\section{$\nabla$}

Esophageal squamous cell carcinoma carries a poor prognosis in symptomatic patients because of late diagnosis and the technical difficulty of surgical resection in patients with locally advanced disease. The median survival in those with advanced disease is less than a year [1]. In contrast, the 5-year survival rate in asymptomatic patients with stage 0 exceeds $95 \%$ [1].

Patients with head and neck cancer have a risk of developing second primary esophageal squamous cell carcinoma with an incidence of 9-44\% [1 10]. The detection of early esophageal squamous cell neoplasms (ESCN) improves the survival rate were detected in 12 patients. Seven lesions (33\%) from four patients were histologically diagnosed as ESCNs (four with high grade dysplasia and three with low grade dysplasia). The other 14 lesions were histologically confirmed as non-neoplastic: active esophagitis, glycogenation with inflammation, acute ulcer, inlet patch, and unremarkable changes. The sensitivity, specificity, PPV, NPV, and accuracy of pCLE vs. dNBI were $83 \%$ vs. $85 \%, 92 \%$ vs. $62 \%, 83 \%$ vs. $54 \%, 92 \%$ vs. $89 \%$, and $89 \%$ vs. $70 \%$, respectively (NS).

Conclusions: Asymptomatic patients with a history of head and neck cancer underwent Lugol's chromoendoscopy based ESCN surveillance. Further characterization of the Lugol's voiding lesions by advanced imaging showed that both pCLE and dNBI provided good sensitivity in diagnosing ESCN, and pCLE tended to provide higher specificity, PPV, and accuracy than dNBI. Perhaps the trend of lower specificity of dNBI in this study was possibly because of the interference from Lugol's stain on the interpretation of intrapapillary capillary loops (IPCLs). Further study is required to seek a significant difference in the performance of dNBI and pCLE in a larger group of patients.

$[11,12]$. Moreover, these ESCNs can be resected by endoscopy techniques such as endoscopic mucosal resection (EMR) and endoscopic submucosal dissection (ESD) [2,13-15]. Therefore, patients with head and neck cancer are recommended to have a surveillance endoscopy for second primary ESCN $[13,16]$.

Lugol's chromoendoscopy, with an excellent sensitivity $(100 \%)$, has been widely used in a protocol for ESCN surveillance $[17,18]$. Lugol's voiding lesions larger than $5 \mathrm{~mm}$ have been reported to be associated with dysplastic change $[17,18]$. However, the specificity of Lugol's chromoendoscopy is considered suboptimal (63-85\%), as many non-neoplastic lesions, such as atrophic change 
and esophagitis, also appeared unstained by Lugol's solution [19-22].

Probe-based confocal laser endomicroscopy (pCLE), allowing real-time histological analysis [23-25], and dual focus narrowband imaging (dNBI) evaluation of vascular networks for the possibility of detecting malignancy, can be adopted to characterize and predict the malignancy of Lugol's voiding lesions [20,21].

To date, there has been no direct comparison between the two modalities in patients with high risk for ESCN undergoing endoscopic surveillance with Lugol's chromoendoscopy. The objective of this study was to compare the diagnostic value of PCLE and dNBI for ESCN diagnosis in patients with a history of previous head and neck squamous cell carcinomas undergoing endoscopic surveillance. All Lugol's voiding lesions larger than $5 \mathrm{~mm}$ were targeted and characterized by these two endoscopic real-time histological readings.

\section{Material and methods}

$\nabla$

\section{Patients}

This study was conducted at the King Chulalongkorn Memorial Hospital, Bangkok from March 2013 to June 2014. Patients over 18 years of age with a histologically confirmed diagnosis of head and neck cancer diagnosed during the period 1 January 2003 to 31 December 2012, at the King Chulalongkorn Memorial Hospital without dysphagia were recruited. Patients' contact information was obtained from the hospital database. Patients with squamous cell cancer of the nasopharynx were excluded because of its poor correlation with a second primary ESCN [6]. Other exclusion criteria were a history of esophageal surgery, esophageal stricture or obstruction, esophageal varices, known cases of esophageal cancer, uncorrectable coagulopathy and thrombocytopenia, pregnancy, thyrotoxicosis, creatinine clearance less than $30 \mathrm{~mL} / \mathrm{min}$, and history of allergy to iodine or fluorescein. The research protocol was approved by the hospital ethical committee and informed consent was given by all patients (NCT02182804).

\section{Study design}

This study was a single-center, nonrandomized, cross-sectional trial on the discrimination performance of dNBI and pCLE for ESCN diagnosis in Lugol's voiding lesions. The Lugol's voiding lesions were examined by dNBI first and, subsequently, by pCLE without randomized crossover because the pCLE technique requires direct contact between the mucosa and the pCLE probe, which could alter the interpretation of intrapapillary capillary loops (IPCLs) by dNBI. Therefore, pCLE could not be performed first.

\section{Sample size calculation and statistical analysis}

The sample size of this pilot study was calculated based on a confidence interval (CI) approach using a formula for $95 \% \mathrm{CI}$ for a single proportion [26]: $\mathrm{p} \pm 1.96 \sqrt{[\mathrm{p}}(1-\mathrm{p}) / \mathrm{n}]$ where "p" is the anticipated value of specificity and " $n$ " is the sample size. The anticipated value of specificity was obtained from the results of previous studies with endoscope-based confocal laser endomicroscopy (eCLE) [25] and dNBI [20] for the screening of esophageal cancer in patients with primary head and neck cancers. To estimate the specificity of pCLE of $95 \%$ to be within a $95 \%$ confidence interval of $\pm 9 \%$ and the specificity of dNBI of $80 \%$ to be within a $95 \%$ confidence interval of $\pm 17 \%$, the calculated sample size for the num- ber of lesions would be 21 lesions. For sample size estimation for number of patients, we inserted an alpha probability of 0.05 , power 0.8 , sensitivity of first test 0.95 , and sensitivity of second test 0.8 , and a minimum of 40 patients was required.

The baseline descriptive data for the patients were analyzed by means and standard deviations for continuous variables, and by percentage and frequency for categorical variables. All of the endoscopic evaluations from both $\mathrm{dNBI}$ and pCLE were compared with the matched histology. By using histology as the gold standard, the sensitivity, specificity, positive predictive value (PPV), negative predictive value (NPV), and accuracy of dBNI and pCLE diagnoses on Lugol's voiding lesions were calculated. The difference of these parameters for dNBI vs. pCLE was compared using McNemar's test. $P$ values less than 0.05 were considered to be statistically significant. We assumed that the pathology of each lesion in the same patient with multiple lesions was independent, and that the evaluation from dNBI was also independent of the subsequent evaluation from pCLE. Ninety-five percent confidence intervals for sensitivity, specificity, PPV, NPV, and accuracy were calculated using the normal approximation interval. Statistical analyses were performed using IBM SPSS software version 17.0 for Windows (IBM Corp., United States).

\section{Instrument and criteria to diagnose ESCN}

All examinations were performed using the GIF-HQ190 EVIS EXERA III gastrointestinal videoscope (Olympus, Tokyo, Japan) with dual focus two-stage optical lens technology $(45 \times$ optical magnification, $75 \times$ with additional digital magnification) allowing a detailed study of esophageal IPCLs, and the Cellvizio gastroflex (Mauna Kea Technology, Paris, France) with $1000 \times$ magnification provided in vivo black and white histological images.

Since all esophageal lesions had already been identified by Lugol's staining, the purpose of dNBI examination was only to characterize the Lugol's voiding lesions and not to detect additional lesions. According to Inoue's classification using NBI with "magnification" as a modality to diagnose ESCN [27], mucosa containing regular IPCLs was considered normal epithelium ( $\bullet$ Fig. 1 a). In contrast, mucosa containing dilatation, tortuosity, caliber change, and variation in shape of the IPCLs was considered neoplastic. In the present study, all Lugol's voiding lesions with two or more of the described abnormal IPCL patterns were considered ESCNs ( $\bullet$ Fig. 1 b).

The pCLE interpretation was based on cellular and vascular criteria. As there were no previous criteria to diagnose ESCN by pCLE, we adopted the criteria from the previous study using eCLE. However, we accepted that there is a certain difference in scanning depth between pCLE and eCLE as pCLE provides a fixed scanning depth of $55-65 \mu \mathrm{m}$, whereas eCLE provides a wider range of adjustable scanning depth $(0-250 \mu \mathrm{m})$. For cellular criteria, normal squamous epithelial cells were homogenous with regular architecture and clearly visible borders of the squamous cells ( $\bullet$ Fig. 2 a). In contrast, the neoplastic epithelium was inhomogeneous with irregular architecture of the squamous cells. In the majority of cases, these cells displayed no clearly visible border between the cells ( Fig. $\mathbf{2 b}$ ). For vascular criteria, normal capillaries appeared regular without fluorescein leakage ( $\bullet$ Fig.3a), whereas neoplastic capillaries were irregular, twisted, dilated, and elongated ( Fig.3b). Occasionally, fluorescein leakage ( $\bullet$ Fig. 3 b (arrow)) could also be observed [17]. 

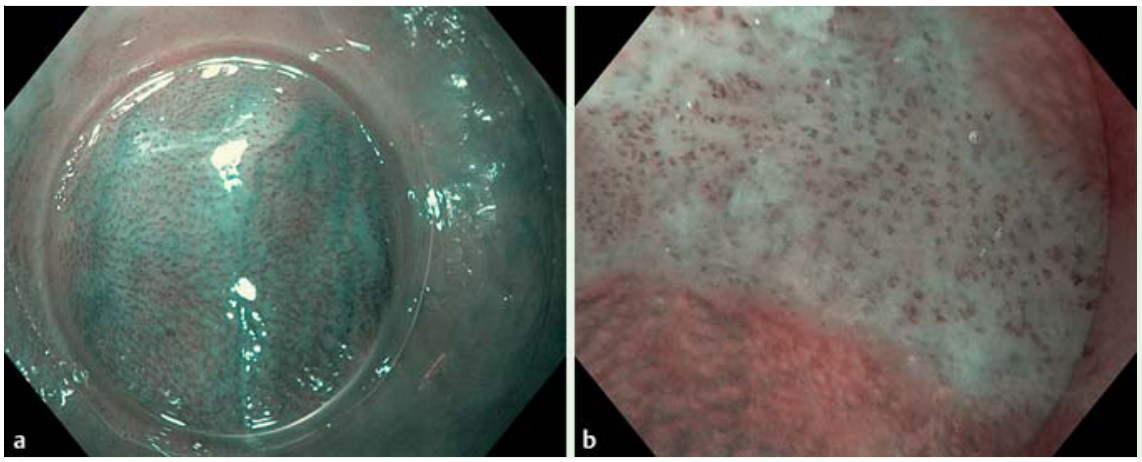

Fig. 1 a Dual focus narrow-band imaging (dNBI) shows the regular intrapapillary capillary loops (IPCLs) in the normal esophageal epithelium. b Dual focus narrow-band imaging (dNBI) shows the dilatation, tortuousity, caliber change, and variation in shape of the IPCLs in the early esophageal squamous cell neoplasm (ESCN).
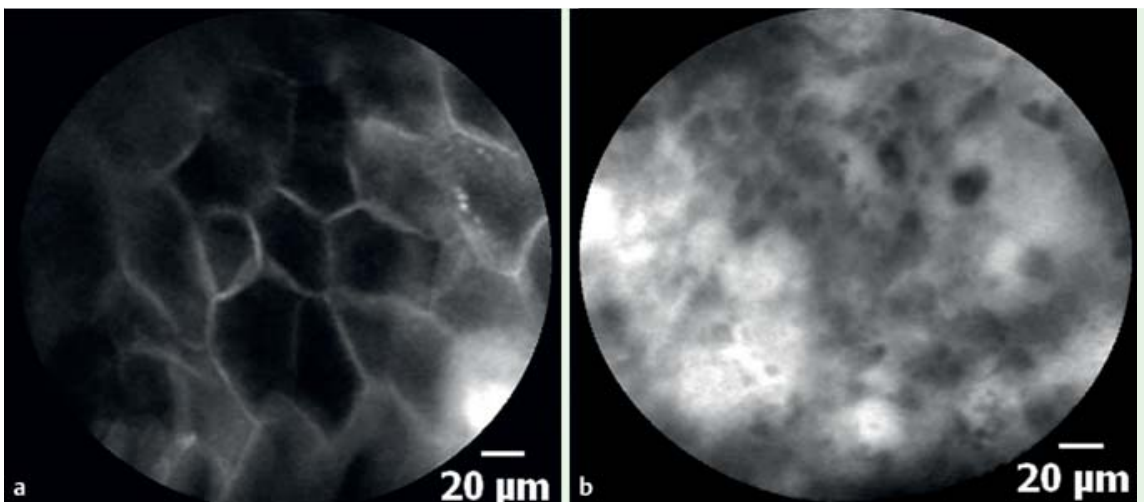

Fig. 2 a Probe-based confocal laser endomicroscopy ( $\mathrm{pCLE}$ ) shows the homogenous squamous epithelial cells with regular architecture and clearly visible borders. b Probe-based confocal laser endomicroscopy ( $\mathrm{pCLE}$ ) shows the inhomogeneous squamous epithelium with irregular architecture and without clearly visible borders between cells in the early esophageal squamous cell neoplasm (ESCN).
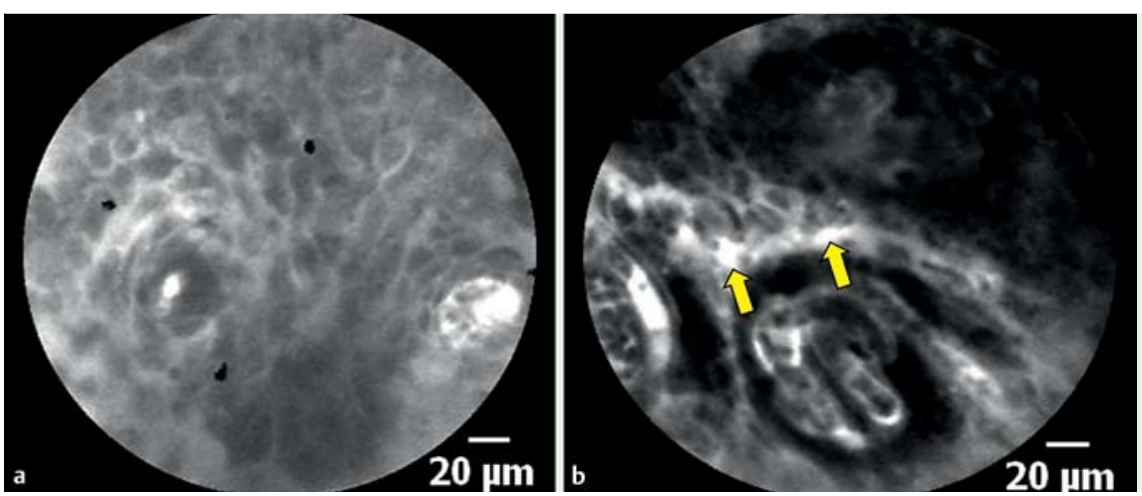

Fig. 3 a Probe-based confocal laser endomicroscopy ( $\mathrm{PCLE}$ ) shows the regular capillary without fluorescein leakage. b Probe-based confocal laser endomicroscopy (PCLE) shows the irregular, twisted, dilated, and elongated capillary in the neoplastic lesion. Fluorescein leakage could also be observed (arrow)

\section{Procedure}

The procedures were performed under conscious sedation with meperidine and midazolam with an additional 10\% lidocaine oral spray. The level of sedation was targeted at moderate to deep sedation in order to obtain satisfactory pCLE images. Propofol was not used for sedation in this study. Initially, standard white light upper endoscopy (WLE) was performed. When lesions, such as demarcated red lesions, elevated or depressed lesions [20], were detected, the size and location, and an image of each of these lesions were recorded as abnormal areas detected by WLE. These findings were later compared and mapped with the subsequent Lugol's voiding lesions. Next, a $0.5 \%$ Lugol's solution was sprayed onto the esophageal mucosa starting from the esophagogastric junction to just below the upper esophageal sphincter (approximately $15 \mathrm{~cm}$ from the incisor) [25]. Under WLE, we recorded the size, location, and images of all of the Lugol's voiding lesions larger than $5 \mathrm{~mm}$. The widest dimension of the Lugol's voiding lesion was determined by comparing with a 5 -mm forceps. The locations of Lugol's voiding lesions were mapped by the distance from the incisor and the relative position to the scope. After having heavily irrigated the mucosa with normal saline, dNBI was used to evaluate the IPCL pattern of the Lugol's voiding lesions by the first endoscopist (PP), who had extensive experience ( $>100$ procedures over a number of years) of performing dNBI examinations in many gastrointestinal structures, including esophageal squamous cell carcinoma, before entering this study.

To avoid a carry-over effect, the lesion was then examined with pCLE by an independent endoscopist (RP) who was blinded to the dNBI result and was called in only after the first endoscopist had finished the dNBI examination and the endoscope had been switched back to white light mode. The endoscopist performing pCLE was also experienced ( $>100$ procedures) and had performed pCLE examinations in many gastrointestinal structures including the esophagus, stomach, and duodenum. However, experience with pCLE for ESCN detection might be at a fundamental stage as this was a pilot study. Although we did not have an objective measurement, we believed that the two endoscopists had comparable experience in diagnosing esophageal squamous cell carcinoma. After intravenously injecting $5 \mathrm{~mL}$ of $10 \%$ fluorescein sodium for 30 seconds, the process to characterize Lugol's voiding lesions was carried out. When there was more than one Lugol's voiding lesion during a single examination, tandem examinations by dNBI and pCLE were performed lesion by lesion from the distal esophagus upwards. We selected up to five lesions per patient for study and this was still manageable without any con- 


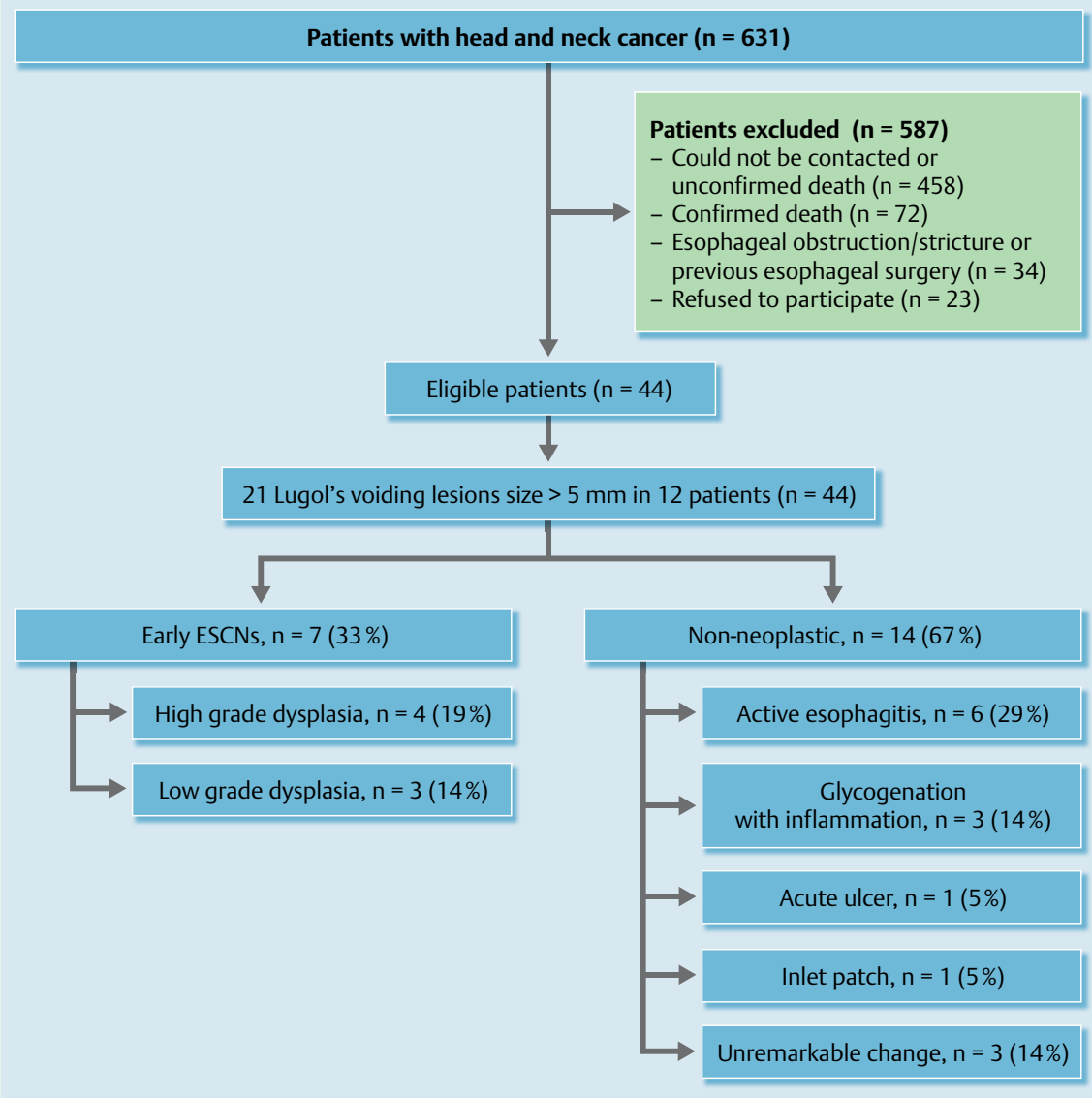

Fig. 4 Diagram of the study population.

fusion in tracking the lesions. The distal tip of the endoscope was fixed on the target Lugol's voiding lesion while the two endoscopists swapped over. Irrigation with saline was used only at that target lesion. After switching endoscopist, additional Lugol's solution spray was used if required.

Finally, all Lugol's voiding lesions larger than $5 \mathrm{~mm}$ were biopsied by the endoscopist performing the pCLE. Mucosal low grade intraepithelial neoplasias and high grade intraepithelial neoplasias, as defined by the revised Vienna classification [28], were used to diagnose ESCNs in the present study. All histologic examinations were performed by an experienced pathologist (NW) who was blinded to the endoscopic results.

\section{Results}

There were 631 patients with a previous history of head and neck cancer in the 10-year record. Three attempts were made to contact the patients through all available phone numbers before considering as failure to contact. Of the 631 patients, 587 were excluded for the following reasons: patients could not be contacted $(n=458)$, death $(n=72)$, esophageal obstruction or stricture, previous esophageal surgery $(n=34)$, and patients who refused to participate $(n=23)$. Finally, 44 asymptomatic patients with a previous history of head and neck cancer were eligible for the study as shown in Fig.4. Demographic and index head and neck cancer data are shown in Table 1 . The majority (86\%) of patients were male with a mean age of 60 years (range $23-77$ years). In total, 27 patients (62\%) were ex-smokers, 12 patients $(27 \%)$ never smoked, and 5 patients (11\%) were current smokers; 17 patients (39\%) were ex-drinkers, 16 patients (36\%) never drank,
Table 1 Characteristics of the enrolled patients $(n=44)$.

\begin{tabular}{|l|l|}
\hline Gender & $38(86)$ \\
\hline Male, $\mathrm{n}(\%)$ & $6(14)$ \\
\hline Female, $\mathrm{n}(\%)$ & 60 (range 23-77, SD 12) \\
\hline Age, years & \\
\hline Index head and neck cancer & $14(32)$ \\
\hline Glottis, $\mathrm{n}(\%)$ & $9(20)$ \\
\hline Oral cavity, $\mathrm{n}(\%)$ & $8(18)$ \\
\hline Tonsil, $\mathrm{n}(\%)$ & $6(14)$ \\
\hline Hypopharynx, $\mathrm{n}(\%)$ & $5(11)$ \\
\hline Tongue, $\mathrm{n}(\%)$ & $2(5)$ \\
\hline Oropharynx, $\mathrm{n}(\%)$ & $38(86)$ \\
\hline Treatment status & $4(9)$ \\
\hline Cured with regular follow-up, $\mathrm{n}(\%)$ & $2(5)$ \\
\hline Under ongoing treatment, $\mathrm{n}(\%)$ & \\
\hline Cured with no follow-up, $\mathrm{n}(\%)$ &
\end{tabular}

and 11 patients (25\%) were current drinkers. Based on the hospital records, the demographic data for excluded patients were not grossly different from that for recruited patients (data not shown).

The endoscopic diagnoses under WLE are shown in $\bullet$ Table 2. One patient developed bleeding after biopsy and was successfully treated with endoscopic clipping.

WLE was able to detect eight lesions in three patients, of which five were elevated lesions and the other three were flat demarcated red lesions. Three of the eight lesions (37.5\%) detected by WLE were confirmed later as ESCNs. There was no advanced esophageal squamous cell carcinoma detected in any patient.

In total, 21 Lugol's voiding lesions larger than $5 \mathrm{~mm}$ were detected in 12 patients (27\%), 11 of whom were male (92\%). The index 
Table 2 Characteristics of 21 biopsied Lugol's voiding lesions among patients with head and neck cancers.

\begin{tabular}{|c|c|c|c|c|c|c|c|c|c|}
\hline Case & Age & Sex & $\begin{array}{l}\text { Location of } \\
\text { head and neck } \\
\text { carcinoma }\end{array}$ & Location & WLE & $\begin{array}{l}\text { IPCL pattern } \\
\text { on dNBI }\end{array}$ & Cellular findings on pCLE & $\begin{array}{l}\text { Vascular findings } \\
\text { on PCLE }\end{array}$ & Histology \\
\hline 1 & 58 & M & Hypopharynx & Middle & Missed & III & $\begin{array}{l}\text { Homogeneous, regular ar- } \\
\text { chitecture, clearly visible } \\
\text { border }\end{array}$ & Regular & $\begin{array}{l}\text { Active } \\
\text { esophagitis }\end{array}$ \\
\hline \multirow[t]{3}{*}{2} & 70 & M & Glottis & Middle & Missed & III & $\begin{array}{l}\text { Homogeneous, regular ar- } \\
\text { chitecture, clearly visible } \\
\text { border }\end{array}$ & Regular & $\begin{array}{l}\text { Glycogena- } \\
\text { tion/inflam- } \\
\text { mation }\end{array}$ \\
\hline & & & Glottis & Middle & Missed & III & $\begin{array}{l}\text { Homogeneous, regular ar- } \\
\text { chitecture, clearly visible } \\
\text { border }\end{array}$ & Regular & $\begin{array}{l}\text { Glycogena- } \\
\text { tion/inflam- } \\
\text { mation }\end{array}$ \\
\hline & & & Glottis & Upper & Missed & III & $\begin{array}{l}\text { Homogeneous, regular ar- } \\
\text { chitecture, clearly visible } \\
\text { border }\end{array}$ & Regular & $\begin{array}{l}\text { Glycogena- } \\
\text { tion/inflam- } \\
\text { mation }\end{array}$ \\
\hline 3 & 71 & M & Hypopharynx & Middle & Missed & III & $\begin{array}{l}\text { Homogeneous, regular ar- } \\
\text { chitecture, clearly visible } \\
\text { border }\end{array}$ & Elongated & $\begin{array}{l}\text { Unremark- } \\
\text { able change }\end{array}$ \\
\hline 4 & 66 & $\mathrm{~F}$ & Oropharynx & Middle & Missed & IV & $\begin{array}{l}\text { Inhomogeneous, irregular } \\
\text { architecture, blurry bor- } \\
\text { der, dark cells }\end{array}$ & $\begin{array}{l}\text { Irregular, elongat- } \\
\text { ed and dilated }\end{array}$ & HGD \\
\hline \multirow[t]{5}{*}{5} & 60 & M & Oral cavity & Upper & Detected & IV & $\begin{array}{l}\text { Inhomogeneous, irregular } \\
\text { architecture, blurry bor- } \\
\text { der }\end{array}$ & $\begin{array}{l}\text { Elongated and } \\
\text { dilated }\end{array}$ & $\begin{array}{l}\text { Active } \\
\text { esophagitis }\end{array}$ \\
\hline & & & & Upper & Detected & IV & $\begin{array}{l}\text { Inhomogeneous, irregular } \\
\text { architecture, blurry bor- } \\
\text { der }\end{array}$ & $\begin{array}{l}\text { Irregular, elongat- } \\
\text { ed, and dilated }\end{array}$ & $\begin{array}{l}\text { Active } \\
\text { esophagitis }\end{array}$ \\
\hline & & & & Middle & Detected & IV & $\begin{array}{l}\text { Inhomogeneous, irregular } \\
\text { architecture, blurry bor- } \\
\text { der }\end{array}$ & $\begin{array}{l}\text { Irregular and dilat- } \\
\text { ed }\end{array}$ & $\begin{array}{l}\text { Active } \\
\text { esophagitis }\end{array}$ \\
\hline & & & & Middle & Detected & IV & $\begin{array}{l}\text { Inhomogeneous, irregular } \\
\text { architecture, blurry bor- } \\
\text { der, dark cells }\end{array}$ & Irregular & Active ulcer \\
\hline & & & & Lower & Detected & IV & $\begin{array}{l}\text { Homogeneous, regular ar- } \\
\text { chitecture, clearly visible } \\
\text { border, dark cells }\end{array}$ & $\begin{array}{l}\text { Irregular, elongat- } \\
\text { ed, and dilated }\end{array}$ & HGD \\
\hline 6 & 58 & M & Oral cavity & Upper & Detected & III & $\begin{array}{l}\text { Homogeneous, regular ar- } \\
\text { chitecture, clearly visible } \\
\text { border, columnar cells }\end{array}$ & Regular & Inlet patch \\
\hline 7 & 60 & M & Glottic & Lower & Missed & III & $\begin{array}{l}\text { Homogeneous (poor im- } \\
\text { age quality) }\end{array}$ & Dilated & LGD \\
\hline \multirow[t]{4}{*}{8} & 63 & M & Supraglottic & Middle & Detected & IV & $\begin{array}{l}\text { Inhomogeneous, irregular } \\
\text { architecture, blurry bor- } \\
\text { der, dark cells }\end{array}$ & $\begin{array}{l}\text { Irregular, elongat- } \\
\text { ed and dilated }\end{array}$ & LGD \\
\hline & & & & Middle & Detected & IV & $\begin{array}{l}\text { Inhomogeneous, irregular } \\
\text { architecture, blurry bor- } \\
\text { der, dark cells }\end{array}$ & $\begin{array}{l}\text { Irregular, elongat- } \\
\text { ed and dilated }\end{array}$ & HGD \\
\hline & & & & Lower & Missed & IV & $\begin{array}{l}\text { Homogeneous, irregular } \\
\text { architecture, blurry bor- } \\
\text { der, dark cells }\end{array}$ & Irregular & LGD \\
\hline & & & & Lower & Missed & IV & $\begin{array}{l}\text { Homogeneous, irregular } \\
\text { architecture, clearly visi- } \\
\text { ble border }\end{array}$ & $\begin{array}{l}\text { Irregular, elongat- } \\
\text { ed and dilated }\end{array}$ & $\begin{array}{l}\text { Unremark- } \\
\text { able change }\end{array}$ \\
\hline 9 & 59 & M & Pyriform & Middle & Missed & IV & $\begin{array}{l}\text { Inhomogeneous, irregular } \\
\text { architecture, blurry bor- } \\
\text { der, dark cells }\end{array}$ & $\begin{array}{l}\text { Irregular, elongat- } \\
\text { ed }\end{array}$ & HGD \\
\hline 10 & 65 & M & Hard palate & Lower & Missed & III & $\begin{array}{l}\text { Inhomogeneous, irregular } \\
\text { architecture, blurry bor- } \\
\text { der, dark cells }\end{array}$ & Regular & $\begin{array}{l}\text { Active } \\
\text { esophagitis }\end{array}$ \\
\hline 11 & 64 & M & Oropharynx & Lower & Missed & N/A & $\begin{array}{l}\text { Homogeneous (poor im- } \\
\text { age quality) }\end{array}$ & $\begin{array}{l}\text { Regular (poor } \\
\text { image quality) }\end{array}$ & $\begin{array}{l}\text { Unremark- } \\
\text { able change }\end{array}$ \\
\hline 12 & 73 & $M$ & Tonsil & Lower & Missed & III & $\begin{array}{l}\text { Homogeneous, irregular } \\
\text { architecture, clearly visi- } \\
\text { ble border }\end{array}$ & Regular & $\begin{array}{l}\text { Active } \\
\text { esophagitis }\end{array}$ \\
\hline
\end{tabular}

WLE, white light endoscopy; IPCL, intrapapillary capillary loop; dNBI, dual focus narrow-band imaging; pCLE, probed-based confocal laser endomicroscopy; HGD, high grade dysplasia; LGD, low grade dysplasia. 
head and neck cancers were hypopharynx $(n=3)$, oral cavity $(\mathrm{n}=$ $3)$, glottis $(n=3)$, oropharynx $(n=2)$, and tonsil $(n=1)$. All of these patients were considered to be cured from the index cancer and had a regular follow-up before entering the present study. All of the positive lesions detected under WLE $(n=8)$ were also Lugol's voiding lesions. The size of the Lugol's voiding lesions ranged from $5 \mathrm{~mm}$ to $26 \mathrm{~mm}$ (mean $10 \mathrm{~mm}$, SD $5.7 \mathrm{~mm}$ ), and were located $15-36 \mathrm{~cm}$ from the incisor (mean $27 \mathrm{~cm}$, SD $5.1 \mathrm{~cm}$ ). The histological results for these Lugol's voiding lesions are shown in - Table 3. There were seven ESCNs consisting of four high grade intraepithelial neoplasias and three low grade intraepithelial neoplasias ( Fig.4). The specificity of the diagnosis for ESCN by Lugol's spray technique was only $33 \%$. There were 14 non-neoplastic lesions consisting of active esophagitis $(n=6)$, glycogenation with inflammation $(n=3)$, acute ulcer $(n=1)$, inlet patch $(n=$ $1)$, and unremarkable changes $(n=3)(\bullet$ Fig.4). [Generally, lesions with glycogenation should appear very dark on Lugol's staining and we did not mention this in the results as we excluded those lesions from our study. However, there were certain lesions that had a combination of inflammation and glycogenation and part of the lesion presented as Lugol's voiding. This in turn leads to Lugol's voiding glycogenation.]

Seven ESCNs were detected in four out of the 44 patients ( $9 \%$ of all screened patients), whose ages ranged from 59 to 66 years. Three of these patients were male. The index head and neck cancers were hypopharynx, oropharynx, oral cavity, and glottis. Two patients had a single lesion, one had two lesions, and another had three lesions. The mean time to diagnose of ESCN was 26 months (18-42 months) after the diagnosis of index head and neck cancer, while the mean interval between endoscopy and the diagnosis of index head and neck cancer in patients without ESCN was 28 months (5-117 months). The size of the lesions ranged from $5 \mathrm{~mm}$ to $26 \mathrm{~mm}$ (mean $14 \mathrm{~mm}$ ) and were located $25-36 \mathrm{~cm}$ (mean $30 \mathrm{~cm}$ ) from the incisor. By using histology as the gold standard, the sensitivity, specificity, PPV, NPV, and accuracy of dNBI were $85 \%, 62 \%, 54 \%, 89 \%$, and $70 \%$, respectively, while those of pCLE were $83 \%, 92 \%, 83 \%, 92 \%$, and $89 \%$, respectively, as shown in Table 4. The treatment for the two patients with a single lesion of ESCN was endoscopic mucosal resection, and the treatment for the two patients with synchronous lesions was surgical resection.

\section{Discussion \\ $\nabla$}

Symptomatic esophageal cancer patients carry a dismal prognosis when they are diagnosed at later stages [2]. Therefore, it is important to have a surveillance protocol for ESCN patients while they are still asymptomatic. The best target population to undergo a surveillance protocol is patients with previous head and neck cancer. Our study population included asymptomatic patients with a previous history of head and neck cancer. By excluding patients with squamous cell cancer of the nasopharynx from our target surveillance, we found the incidence rate of ESCNs to be $9 \%$, which was relatively lower than the incidence rate reported by Priante et al. [1]. In their study, they reported an incidence rate of a second primary esophageal cancer in the range from $9 \%$ to $44 \%$. The explanation for the higher incidence in other studies is that they also recruited cases with symptomatic esophageal cancer $[1,8,20]$. In keeping with the previous report, the mean interval after diagnosis of index head and neck cancer in our se-
Table 3 Histological results for Lugol's voiding lesions $(n=21)$.

\begin{tabular}{|ll|}
\hline Histological results & Number of lesions (\%) \\
\hline High grade intraepithelial neoplasia/carcinoma & $4(19)$ \\
\hline Low grade intraepithelial neoplasia & $3(14)$ \\
\hline Active esophagitis & $6(29)$ \\
\hline Inlet patch & $1(5)$ \\
\hline Glycogenation with inflammation & $3(14)$ \\
\hline Unremarkable change & $3(14)$ \\
\hline Acute ulcer & $1(5)$ \\
\hline
\end{tabular}

Table 4 Performance of pCLE and dNBI for ESCN detection in esophageal Lugol's voiding lesions.

\begin{tabular}{|lll|}
\hline & PCLE & dNBI \\
\hline Sensitivity $(95 \% \mathrm{Cl}), \%$ & $83(44-97)$ & $85(49-97)$ \\
\hline Specificity $(95 \% \mathrm{Cl}), \%$ & $92(65-99)$ & $62(35-82)$ \\
\hline PPV $(95 \% \mathrm{Cl}), \%$ & $83(44-97)$ & $54(28-79)$ \\
\hline NPV $(95 \% \mathrm{Cl}), \%$ & $92(65-99)$ & $89(57-98)$ \\
\hline Accuracy $(95 \% \mathrm{Cl}), \%$ & $89(67-97)$ & $70(48-85)$ \\
\hline
\end{tabular}

$\mathrm{Cl}$, confidence interval; $\mathrm{PCLE}$, probe-based confocal laser endomicroscopy; dNBI, dual focus narrow-band imaging; NVP, negative predictive value; PPV, positive predictive value; ESCN, early esophageal squamous cell neoplasm. All $P$ values $>0.05$.

ries was not different from the series reported by Schwartz et al. [10] (26 months, range 18-42 months).

This study confirms the suboptimal detection rate for ESCNs by standard WLE, as WLE detected only three of seven ESCNs (43\%). The sensitivity of WLE in our study was comparable to that in previous studies, which was reported to be $55-66 \%[20,27]$. Although Lugol's spray has been promoted as a technique to improve the sensitivity for ESCN detection, the specificity of Lugol's chromoendoscopy for the diagnosis of esophageal squamous neoplasms was previously reported to be suboptimal at $63-85 \%$ as non-neoplastic lesions were also diagnosed as Lugol's voiding lesions $[18,19,21,28]$. We proposed that real-time endoscopy could be an adjunctive method that may improve the specificity for predicting the pathology of Lugol's voiding lesions. Currently, there are many available techniques, such as magnifying digital chromoendoscopy (NBI, Fujinon intelligent chromoendoscopy (FICE), and the Pentax i-SCAN system), confocal laser endomicroscopy, and endocytoscopy. The advantages of these endoscopic modalities over WLE are the ability to magnify and depict the early neoplasm, to portray the cells and their pattern, to detect the abnormal structure of neoplastic capillaries, and to detect early vascular leakage from abnormal capillaries. In this study, we directly compared the diagnostic capability of pCLE and dNBI in Lugol's voiding lesions. In our study, only one-third of Lugol's voiding lesions larger than $5 \mathrm{~mm}$ were ESCNs. Many Lugol's voiding lesions in this study were active esophagitis and unremarkable changes that could have resulted from the radiation therapy [29], resulting in the lower specificity of Lugol's evaluation. This issue addresses the necessity to characterize Lugol's voiding lesions in order to avoid unnecessary biopsies. The abnormal vascular pattern studied by dNBI and pCLE can help distinguish neoplastic from inflammatory lesions. Moreover, the cellular features can also be additionally studied by pCLE. However, some cardinal features, such as identification of the inflammatory cells in esophagitis and evaluation of the nuclear-cytoplasmic ratio, nuclear pleomorphism, and hyperchromatism in order to deter- 
mine the degree of dysplasia in neoplastic lesions, cannot be appreciated by the current model of pCLE.

The sensitivity, specificity, and accuracy of pCLE in our series using cellular and vascular criteria to predict ESCN were $83 \%, 92 \%$ and $89 \%$, respectively. The study by Pech et al. [25], which investigated 43 Lugol's voiding lesions larger than $5 \mathrm{~mm}$ in 21 patients using eCLE, yielded sensitivity, specificity, and accuracy of $100 \%$, $87 \%$, and $95 \%$, respectively. Although the results from the two studies were comparable, we believe that it might have been more challenging to detect ESCN in our study because our patients were all asymptomatic and had not been subjected to endoscopy previously, whereas the patients in the previous study [25] were already suspected of having ESCN from endoscopy performed before beginning the new study.

The sensitivity of dNBI in this study, using the criteria of two or more abnormal IPCL patterns (corresponding to Inoue's classification type IV), is comparable to that of previous studies ( $85 \%$ vs. $91-100 \%$ ), but, unfortunately, the specificity and accuracy are lower (62\% vs. $80-95 \%$ and $70 \%$ vs. $95 \%$, respectively) [ 20 , 21]. Although the differences were not statistically significant, we found a trend of lower specificity, PPV, and accuracy of dNBI than for PCLE to diagnose ESCN. We speculate that the lower specificity, PPV, and accuracy of dNBI in this study were possibly because of the interference from Lugol's stain on the interpretation of IPCL. Another disadvantage of dNBI compared with pCLE is its inability to read cellular morphology such as the abnormal squamous cells because its magnification $(75 \times)$ is not sufficiently high to evaluate the structure of cells. In our opinion, the combination of abnormal cellular and IPCL patterns is very helpful in diagnosing ESCN, and pCLE better serves this purpose.

Our study has several limitations. First, this was a pilot test on pCLE for ESCN detection as there were only scarce data available for this modality. Although, we applied the same criteria based on a previous study using eCLE, in PCLE with its fixed and narrower level of scanning depth when compared with eCLE, it was possible that the sensitivity to detect ESCN by pCLE would be lower. Second, our sample size was small, as patients with head and neck cancer have poor survival and many were not eligible for the study because of our very strict inclusion criteria. Third, we did not randomly assign the order of dNBI and pCLE because pCLE application must be in direct contact with the lesion. This, in turn, may alter the IPCL pattern, which would be read by the subsequent dNBI. Therefore, we always had to begin our study with dNBI followed by pCLE. However, to prevent an interpretation bias, the second endoscopist performing the pCLE examination was never told about the earlier dNBI results. Fourth, as mentioned earlier, the Lugol's voiding lesions were sometimes not completely washed out before dNBI examination. Despite using a low concentration of Lugol's solution ( $0.5 \%$ ) and with vigorous irrigation with normal saline before dNBI examination, Lugol's iodine significantly influenced the observation of IPCL structure which led to suboptimal dNBI function. Thus, this study could not be presented as advancing the field especially in NBI outcome. Although, the literature had shown that a pink color sign, which was a completely unstained area after the brown color of iodine solution had faded, was highly specific for diagnosing high grade dysplasia and squamous cell carcinoma [30]. Unfortunately, in our study, we did not observe pink color in any high grade intraepithelial neoplasia $(n=4)$ and we did not have any intramucosal cancer. Perhaps the number of positive cases might be too low to discover this phenomenon. Fortunately, we observed that the pCLE evaluation was not affected by the remnant
Lugol's stain. Finally, this study was not designed to calculate the cost effectiveness of the additional procedures that require sophisticated devices such as dNBI and pCLE. At the time of this study in Thailand, this technique, in particular pCLE, was more expensive to perform than a routine biopsy with pathological analysis (300 USD vs. 40 USD) and took longer procedural time than a routine biopsy (40 minutes vs. 15 minutes). However, we envisage that, as the technology progresses and with increased experience of the operator, in time, the cost of pCLE and duration of the procedure may be justified for routine practice. Therefore, a future study, which directly addresses this issue by calculating the number of patients with a previous history of head and neck cancer to be screened for one positive ESCN, is necessary before implementing this protocol into real practice.

Without prior Lugol's spray and the pCLE examination, we propose that dNBI can be useful as the primary modality to detect and characterize suspected ESCN lesions. However, Lugol's chromoendoscopy still provides higher sensitivity than that of the NBI examination and is considered to be the gold standard in ESCN detection $[20-22,28,31]$. Takenaka et al. [21] reported the usefulness of Lugol's chromoendoscopy to detect additional low grade and high grade intraepithelial neoplasias (ESCN) after NBI examination. They demonstrated that the overall sensitivity of Lugol's chromoendoscopy vs. NBI examination to detect esophageal squamous cell carcinoma, including ESCN, was $100 \%$ vs. $91 \%$ [21]. In our opinion, Lugol's spray can be subsequently added to detect the NBI-negative ESCNs. However, these additional lesions should be further studied by confocal laser examination to minimize the number of unnecessary biopsies. In contrast, if there are no additional lesions detected by Lugol's chromoendoscopy, the pCLE examination can be omitted.

In conclusion, pCLE provides a trend of higher specificity and accuracy than dNBI to differentiate between neoplastic and nonneoplastic lesions in Lugol's voiding lesions in patients with a history of head and neck cancer. As a result of the incomplete wash out of Lugol's spray, the performance of dNBI for the examination of a capillary network in this situation is suboptimal. Future study is needed to seek a significant difference in the performance between dNBI and PCLE in a larger population.

\section{Competing interests: None}

\section{Acknowledgments \\ $\nabla$}

This work was funded by the Ratchadaphiseksomphot Endowment Fund of Chulalongkorn University (CU-57-001-HR) and The Gastroenterological Association of Thailand.

\section{References}

1 Priante AV, Castilho EC, Kowalski LP. Second primary tumors in patients with head and neck cancer. Curr Oncol Rep 2011; 13: 132-137

2 Enzinger PC, Mayer RJ. Esophageal cancer. NEJM 2003; 349: 2241 2252

3 Lee JM, Turini M, Botteman MF et al. Economic burden of head and neck cancer. A literature review. Eur J Health Econ 2004; 5: 70 - 80

4 Vokes EE, Weichselbaum RR, Lippman SM et al. Head and neck cancer. NEJM 1993; 328: 184-194

5 Slaughter DP, Southwick HW, Smejkal W. Field cancerization in oral stratified squamous epithelium; clinical implications of multicentric origin. Cancer 1953; 6: 963-968

6 Chen MC, Chen PT, Chan $\mathrm{CH}$ et al. Second primary esophageal or lung cancer in patients with head and neck carcinoma in Taiwan: incidence 
and risk in relation to primary index tumor site. J Cancer Res Clin Oncol 2011; 137: $115-123$

7 Morris LG, Sikora AG, Hayes RB et al. Anatomic sites at elevated risk of second primary cancer after an index head and neck cancer. Cancer Causes Control 2011; 22: 671 -679

8 Wang WL, Lee CT, Lee YC et al. Risk factors for developing synchronous esophageal neoplasia in patients with head and neck cancer. Head Neck 2011; 33: 77-81

9 Tubiana M. Can we reduce the incidence of second primary malignancies occurring after radiotherapy? A critical review. Radiother Oncol 2009; 91: 4-15; discussion 11-13

10 Schwartz LH, Ozsahin M, Zhang GN et al. Synchronous and metachronous head and neck carcinomas. Cancer 1994; 74: 1933-1938

11 Atabek U, Mohit-Tabatabai MA, Rush BF et al. Impact of esophageal screening in patients with head and neck cancer. Am Surg 1990; 56: 289-292

12 Rennemo E, Zatterstrom $U$, Boysen $M$. Impact of second primary tumors on survival in head and neck cancer: an analysis of 2,063 cases. Laryngoscope 2008; 118: 1350 - 1356

13 Morimoto M, Nishiyama K, Nakamura S et al. Significance of endoscopic screening and endoscopic resection for esophageal cancer in patients with hypopharyngeal cancer. Jpn J Clin Oncol 2010; 40: 938-943

14 Katada C, Muto M, Momma $\mathrm{K}$ et al. Clinical outcome after endoscopic mucosal resection for esophageal squamous cell carcinoma invading the muscularis mucosae - a multicenter retrospective cohort study. Endoscopy 2007; 39: 779-783

15 Wang GQ Abnet CC, Shen Q et al. Histological precursors of oesophageal squamous cell carcinoma: results from a 13 year prospective follow up study in a high risk population. Gut 2005; 54: 187-192

16 Dubuc J, Legoux JL, Winnock $M$ et al. Endoscopic screening for esophageal squamous-cell carcinoma in high-risk patients: a prospective study conducted in 62 French endoscopy centers. Endoscopy 2006; 38: $690-695$

17 Liu H, Li YQ Yu T et al. Confocal laser endomicroscopy for superficial esophageal squamous cell carcinoma. Endoscopy 2009; 41: 99-106

18 Hashimoto CL, Iriya $K$, Baba ER et al. Lugol's dye spray chromoendoscopy establishes early diagnosis of esophageal cancer in patients with primary head and neck cancer. Am J Gastroenterol 2005; 100: 275 282
19 Freitag CP, Barros SG, Kruel CD et al. Esophageal dysplasias are detected by endoscopy with Lugol in patients at risk for squamous cell carcinoma in southern Brazil. Dis Esophagus 1999; 12: 191 - 195

20 Lee CT, Chang CY, Lee YC et al. Narrow-band imaging with magnifying endoscopy for the screening of esophageal cancer in patients with primary head and neck cancers. Endoscopy 2010; 42: 613-619

21 Takenaka R, Kawahara Y, Okada $\mathrm{H}$ et al. Narrow-band imaging provides reliable screening for esophageal malignancy in patients with head and neck cancers. Am J Gastroenterol 2009; 104: 2942 - 2948

22 Ide E, Maluf-Filho F, Chaves DM et al. Narrow-band imaging without magnification for detecting early esophageal squamous cell carcinoma. World J Gastroenterol 2011; 17: 4408-4413

23 Evans JA, Nishioka NS. Endoscopic confocal microscopy. Curr Opin Gastroenterol 2005; 21: 578-584

24 Polglase AL, McLaren WJ, Skinner SA et al. A fluorescence confocal endomicroscope for in vivo microscopy of the upper- and the lower-Gl tract. Gastrointest Endosc 2005; 62: 686-695

25 Pech O, Rabenstein T, Manner $\mathrm{H}$ et al. Confocal laser endomicroscopy for in vivo diagnosis of early squamous cell carcinoma in the esophagus. Clin Gastroenterol Hepatol 2008; 6: 89-94

26 Thabane L, Ma J, Chu R et al. A tutorial on pilot studies: the what, why and how. BMC Med Res Methodol 2010; 10: 1

27 Uedo N, Fujishiro M, Goda K et al. Role of narrow band imaging for diagnosis of early-stage esophagogastric cancer: current consensus of experienced endoscopists in Asia-Pacific region. Dig Endosc 2011; 23: $58-71$

28 Lee YC, Wang CP, Chen CC et al. Transnasal endoscopy with narrowband imaging and Lugol staining to screen patients with head and neck cancer whose condition limits oral intubation with standard endoscope (with video). Gastrointest Endosc 2009; 69: 408-417

29 Yazbeck VY, Villaruz L, Haley $M$ et al. Management of normal tissue toxicity associated with chemoradiation (primary skin, esophagus, and lung). Cancer J 2013; 19: 231 - 237

30 Shimizu Y, Omori T, Yokoyama A et al. Endoscopic diagnosis of early squamous neoplasia of the esophagus with iodine staining: high-grade intra-epithelial neoplasia turns pink within a few minutes. J Gastroenterol Hepatol 2008; 23: 546-550

31 Nagami $Y$, Tominaga $K$, Machida $H$ et al. Usefulness of non-magnifying narrow-band imaging in screening of early esophageal squamous cell carcinoma: a prospective comparative study using propensity score matching. Am J Gastroenterol 2014; 109: 845-854 